\title{
中国北方土地利用/覆盖变化的情景模拟与预测
}

李月臣 ${ }^{(囚)}$, 何春阳 ${ }^{(3)}$

(1) 重庆大学资源及环境学院, 重庆 400044;

(2) 重庆师范大学地理科学学院, GIS 应用研究重庆市重点实验室, 重庆 400047;

(3) 北京师范大学资源学院, 北京 100875

E-mail: liyuechen@cqnu.edu.cn

2007-09-27 收稿, 2007-12-12 接受

重庆市教育委员会科学技术研究项目(批准号: KJ070811)、中国科学院杰出海外学者基金(批准号: 2001-1-13)和国家重点基础研究发展计划 项目(批准号: 2006CB400505)资助

摘要 以北方 13 省(市)为研究区, 借助系统动力学(SD: System Dynamics)、人工神经网络 (ANN: Artificial Neural Network)和元胞自动机(CA: Cellular Automata)模型建立了 “自上 而下“和“自下而上”相结合, 数量变化与空间分布相结合的不同情景下土地利用/覆盖变化 时空演变规律的动态模拟模型, 并对研究区多种土地利用/覆盖类型变化的时空特征进行 模拟. 模型充分发挥了各子模型的特点和优势, 综合了土地利用/覆盖变化的宏观驱动因 素与微观格局演化特征, 较全面地考虑了多种土地利用/覆盖变化驱动因子, 并引入 CA 模型中, 利用 BP 神经网络简化了 CA 模型模拟过程中参量权重确定问题, 提高了参量权 值确定的精度和模拟结果的可靠性, 模拟精度约 74\%, 在一定程度上反映了大区域土地 利用/覆盖变化的空间格局演变特征, 对脆弱生态区土地利用/覆盖变化的复杂性和生态环 境响应研究具有一定参考价值. 模拟结果表明, 未来 $30 \mathrm{a}$ 中城建用地、林地、水体将明显 增加, 耕地和未利用地将不断减少, 草地的数量则在波动变化中相对保持稳定; 空间上, 农牧交错带和东-南部地区变化最为显著.

关键词

土地利用/覆盖变化

情景模拟与预测

BP 神经网络

元胞自动机

系统动力学

北方 13 省(市)
土地利用 $/$ 覆盖变化 (LUCC: Land Use/Cover Change)是由一组交互作用、相互依存的要素通过交 换能量、物质、信息形成的时空复杂系统 ${ }^{[1]}$, 建立模 拟模型是LUCC研究的有效手段 ${ }^{[2,3]}$, 在LUCC复杂性 认识基础上的对未来LUCC进行情景模拟, 不仅是深 入理解LUCC机制的关键, 而且对制定合理的土地利 用决策也具有重要指导意义. 一些学者在这一领域 进行了有意义的研究, 同时又都存在一些不足之处. 如国际上具有代表性的CLUE(the Conversion of Land Use and its Effect)模型, 具有较强的模拟不同尺度土 地利用情景格局的能力, 但在局部土地利用格局的 演化分配上主要以统计和经验模型为基础, 难以充 分反映土地利用/覆盖微观格局演化的复杂性 ${ }^{[4]}$. 何 春阳等人 ${ }^{[5]}$ 发展的大都市区城市扩展CEM (City Ex- pansion model in Metropolitan area)模型, 具有一定反 映土地利用/覆盖微观格局演化复杂性特征的能力, 但在土地利用/覆盖宏观驱动因素复杂性的表现上比 较薄弱; LUSD(Land Use Scenarios Dynamics model) 模型 “6]对综合应用“自上而下”与“自下而上”相结合 进行土地利用情景模拟进行了探讨, 但该模型是一 个十分简化的模型, 气候、降水等自然因子均未加以 考虑, 微观格局演化模拟中, 各变量参数的确定也有 一些不足之处. 目前, 尽管已有不少有价值的LUCC 模拟研究工作, 但明确地针对LUCC机理构建的模型 还很少, 真正将LUCC与其空间分布相结合, 探讨不 同情景下LUCC的时空演变规律的动态模型更不多 见 ${ }^{[7,8]}$. 区域LUCC受到不同尺度的自然和人文因素 的综合作用, 其变化过程的驱动机制十分复杂 ${ }^{[9]}$. 因 
此, 如何充分反映土地利用/覆盖变化的宏观驱动因 素复杂性和微观格局演化过程复杂性特征, 提高区 域LUCC模拟模型的可靠性，仍然是区域LUCC模拟 模型研究叹待解决的问题 [10].

LUCC动态预测与模拟主要包括两方面的内容: 一是数量预测; 二是未来空间格局模拟. 随着研究的 深入, LUCC研究逐渐从简单的数量预测转向复杂的 时空格局的演变模拟. LUCC 时空模拟模型主要有 4 种类型, 即经验统计模型、随机模型、动力学模型和 主体行为模型 ${ }^{[11]}$. 生态环境和社会经济过程的相互 作用是导致土地利用/覆盖格局时空变化的根本动力. 基于过程的动力学模拟模型能够有效的模拟这些过 程并预测其未来的发展动态和特征 ${ }^{[12]}$. 动力学模型 主要有两种代表方向, 一是自上而下的基于微分方 程的动力学模型, 一是自下而上的离散动力学模型 [13]. 前者比较有代表性的主要有系统动力学模型 (SD: System Dynamics)和神经网络模型(ANN: Artificial Neural Network), 后者则以元胞自动机(CA: Cellular Automata)模型为典型代表.

$\mathrm{SD}$ 描述了系统各状态变量的变化率对各状态变 量或特定输入变量的依存关系 [14]. 它考虑的是整个 系统的最佳目标, 因而非常适合进行诸如包括多个 子系统在内的土地利用/覆盖等自然-社会经济复杂系 统的综合研究 ${ }^{[15]}$. 传统的SD模型解决的是土地利用/ 覆盖数量变化的预测问题, 而对于模拟LUCC空间格 局演变的能力较弱. ANN是一种以生物体的神经系统 工作原理为基础的模型, 通常采用非线性函数, 因此 其动态运行构成了非线性动力学系统, 可以模拟如 土地利用/覆盖这类大规模的非线性复杂系统, 不足 之处在于对训练样本的数量和质量要求较高. 在 LUCC研究中, ANN多见于对土地利用/覆盖分类方面 的探讨, 随着相关理论和实践工作的深入, 逐渐应用 于LUCC 情景预测与模拟研究 ${ }^{[2]}$. 作为一个典型的复 杂系统, LUCC是空间个体相互作用的结果. 因此, 从 空间个体行为的微观角度入手, “自下而上”研究 LUCC 是深入理解其空间动态演变特征的重要方法 [13]. CA 是一种时间、空间、状态都离散，(空间上的) 相互作用和(时间上的)因果关系皆局部的格网动力 学模型, 它“自下而上”的研究思路, 强大的复杂计算 功能、固有的并行计算能力、高度动态性以及具有空 间概念等特征, 使得它在模拟空间复杂系统的时空 演变方面具有很强的能力, 对于LUCC这类复杂系统
的动力学及其空间行为的研究是非常有价值的工具. $\mathrm{CA}$ 在城市增长、扩散和模拟方面研究最早, 最为深 $\lambda^{[13]}$, 在模拟多种土地利用/覆盖类型变化的研究中 的应用还不多见.

地球表面具有高度异质性，不同的地区LUCC都 会表现出不同的特征.因此, 选择典型地区, 探讨发 展土地利用/覆盖情景模型, 预测不远将来不同情景 下的土地利用/覆盖时空变化格局, 考察和评估土地 利用/覆盖系统变化的现实和潜在生态环境影响和反 馈过程, 对于揭示土地利用/覆盖系统与陆地生态系 统之间相互作用机制具有十分重要的意义. 北方 13 省 (市)(北京、天津、河北、山西、内蒙古、吉林、辽宁、 黑龙江、陕西、甘肃、宁夏、青海和新疆)地跨湿润、 半湿润、半干旱和干旱 4 个干湿地带, 气候的地域差 异性和过渡性明显, 地表植被类型多样. 有大面积的 耕地、林地、草原和裸地, 大部分地区处在农牧交错 带上, 是中国境内对全球变化反应较为敏感的地区, 生态环境脆弱. 在土地利用方式上, 区内不但有农有 牧, 而且许多地区农牧交错, 时农时牧. 土地利用活 动主要以短期经济效益为主, 忽视了北方脆弱的生 态地理条件. 不合理的土地利用造成的地表植被破 坏、土壤沙化、沙尘暴肆虐等生态环境问题一直比较 突出, 近些年实施的一系列生态工程对中国北方土 地利用/覆盖的方式、强度和格局也产生了重要的影 响. 这些变化对其他区域甚至全球的生物、物理和化 学过程的潜在影响和响应逐渐引起了人们的关注 ${ }^{[16]}$. 因此, 加强对中国北方 13 省(市)土地利用/覆盖格局 特征、变化强度和过程的研究, 进而认识和理解该地 区土地利用/覆盖的生态环境响应机制, 寻求中国北 方生态安全条件下的土地利用/覆盖优化格局, 具有 重要的理论和现实意义.

基于上述分析, 本文以北方 13 省(市)为研究区, 借助 SD, ANN 和 CA 模型尝试建立“自上而下”和“自 下而上”相结合, 充分反映土地利用/覆盖系统变化的 宏观驱动因素复杂性和微观格局演化过程复杂性特 征, 将土地利用/覆盖数量变化与其空间分布相结合, 探讨不同情景下 LUCC 的时空演变规律的动态模型, 并对研究区 LUCC 的时空特征进行模拟研究.

\section{LUCC 情景模拟与预测模型}

模型的假设条件为: 区域LUCC 是受该区域土地 利用/覆盖需求驱动的, 且区域土地利用/覆盖空间分 
布格局总是和土地需求以及该区域的自然环境和社 会经济状况处于动态平衡之中; 每个研究单元(栅格) 认为是土地利用/覆盖类型的均质空间, 由栅格上主 要的土地利用/覆盖类型代表该单元的土地利用/覆盖 状况 117$]$. 在此假设的基础上, 模型由两个相对独立 的模块组成: 数量预测(非空间需求)模块和空间模拟 (空间分配)模块(见图 1).

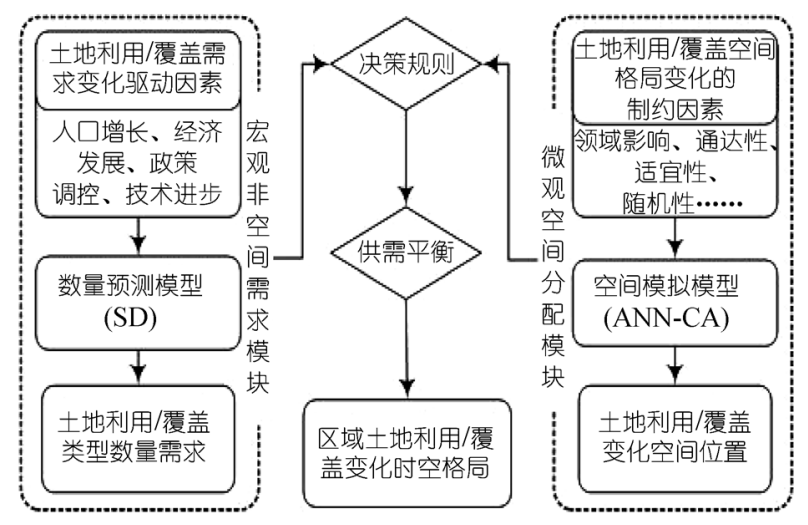

图 1 模型基本结构

\section{1 宏观非空间需求模块设计}

非空间模块在聚集的水平上计算各类土地利用/ 覆盖类型的面积变化, 预测未来不同情景下各种土 地利用/覆盖类型的数量需求. 对于土地利用/覆盖需 求模块, 本文采用作者前期的研究成果 ${ }^{[6,18]}$, 以SD模 型模拟的不同情景下研究区LUCC的数量结果作为 宏观需求模块计算的结果直接输入到微观空间分配 模块.

\section{2 微观空间分配模块设计}

土地利用/覆盖空间分配模块是在分析土地利用/ 覆盖空间分布与其制约因素直接关系的基础上, 生 成不同土地利用/覆盖类型概率分布适宜图, 衡量不 同土地利用/覆盖类型在每个空间单元(栅格)分布的 适宜性程度. CA模型在LUCC研究中具有较大的优势, 但以往的研究中侧重于利用 $C A$ 模型模拟单一的城市 扩展 ${ }^{[5,19 ~ 23]}$, 在模拟多种土地利用/覆盖类型变化研 究中的应用还比较少见, 近些年来将 $\mathrm{CA}$ 模型应用于 模拟多种土地利用/覆盖类型之间的演变逐渐吸引了 许多学者的注意. 本文重点讨论空间分配模块中如 何基于BPNN-CA模型对输入的各土地利用/覆盖类 型需求变化在栅格空间系统的各候选单元进行分配, 从而实现对土地利用/覆盖时空动态变化的模拟.

$\mathrm{CA}$ 在进行空间模拟时需要用到很多空间变量,
而不同的变量在模型中的作用又不尽相同. CA模型 模拟的精度很大程度上受各变量参数设置是否合理 的制约. 只有获得合适的变量参数才能得到接近实 际的模拟结果. 但是目前, 对如何合理设置CA模型中 各变量参数的研究较少, 一般以人为主观赋值为主. 尽管有些学者提出了一些方法, 但都具有一定的局

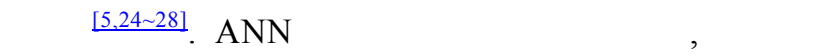
般回归分析更适合模拟复杂的变量系统. 此外, ANN 具有自学习、自组织能力, 不需事先假定一个特定的 模型，极大地简化了模型数据分析所需的建模工作. BP(Back Propagation)神经网络(BPNN)是神经网络研 究中最深入, 应用最广泛的一种模型, 具有广泛的适 应性和有效性, 因此, 本文采用BP神经网络来获取 $\mathrm{CA}$ 模型中各空间变量的作用参数, 然后依据CA模型 的原理进行土地利用/覆盖变化空格格局演变的模拟 研究.

(i) BPNN-CA模型设计. 模块分为 2 个部分, 一是利用选取的样本对 BP神经网络进行训练, 当网 络稳定时即可获取参与空间模拟的各空间变量的权 值参数; 二是把BP神经网络获得的权值参数输入到 $\mathrm{CA}$ 模型中进行土地利用/覆盖时空格局变化的空间 模拟. BP神经网络最终的输出 $O_{o}$ 是一个概率数值, 即 在给定的输入条件下模拟单元转化为某种土地利用/ 覆盖类型的概率, 这里采用最为常用的 $S$ 型(Sigmoid) 函数作为激发函数来计算转移概率 [29 31]. 由于土地 利用/覆盖变化具有一定的继承性 $(k)$, 即保持原有土 地利用/覆盖类型的能力, 可以根据各土地利用/覆盖 类型继承性的强弱分别定义为 $0 \sim 1$ 之间的一个常量, 值越大说明其保持原有类型的能力越强, 反之则弱. 该参数的设置主要依靠研究者对研究地区土地利用/ 覆盖变化的理解, 也可以在模型检验的过程中进行 调试. 此外, 土地利用/覆盖时空格局的转化有时具 有一定的随机性, 加入随机振荡参数 $(r)$ 进行调节模 拟的结果更符合实际情况. 因此, 本部分的研究中也 将随机振荡参数引入到空间分配模型中: $r$ $=[-\ln (\text { rand })]^{a}$, 其中, rand 是 $0 \sim 1$ 之间的随机数, $a$ 为 控制随机干扰参数作用程度大小的常数. 基于上述 分析, $t$ 时刻某栅格单元 $(m, n)$ 在给定的输入条件下转 化为某种土地利用 $/$ 覆盖类型 $l$ 的概率 ${ }^{t} P_{(m, n)}^{l}$ 可以表达 为 


$$
{ }^{t} P_{(m, n)}^{l}=\left(O_{o}+k\right) \cdot r=\left(\frac{1}{1+\mathrm{e}^{-I_{o}}}+k\right) \cdot[-\ln (\text { rand })]^{a},
$$

根据上式即可计算得到 $t$ 时刻各土地利用/覆盖类型 空间分布概率图. 对于某一栅格单元, 在 $t$ 时刻只能 分配为一种土地利用/覆盖类型, 可以根据转化概率 的最大值确定该单元的分配类型. 空间分配模块允 许研究者根据研究区土地利用/覆盖变化的实际情况 定义转化规则, 对不同土地利用/覆盖类型转化的难 易程度和先后顺序进行控制(见图 2).

(ii) 转化规则定义. (1) 转化保护规则: 对于
一般不会转变为其他土地利用/覆盖类型的地类, 如 城镇和建设用地, 除非将来这类土地利用/覆盖类型 的需求面积有所减少，否则模拟期内不考虑该类型 的转出变化; (2) 优先顺序规则: 研究区土地利用/覆 盖类型按照城镇及建设用地 $\rightarrow$ 水体 $\rightarrow$ 耕地 $\rightarrow$ 草地 $\rightarrow$ 林地 $\rightarrow$ 未利用地的顺序进行空间分配; (3) 转化概率 最大规则: 依据转化概率最大原则, 如城镇及建设用 地的空间分配, 首先通过逐栅格单元比较找出城镇 及建设用地转化概率最大的栅格单元, 然后按照转 化概率由大到小的顺序进行空间分配，直至满足总

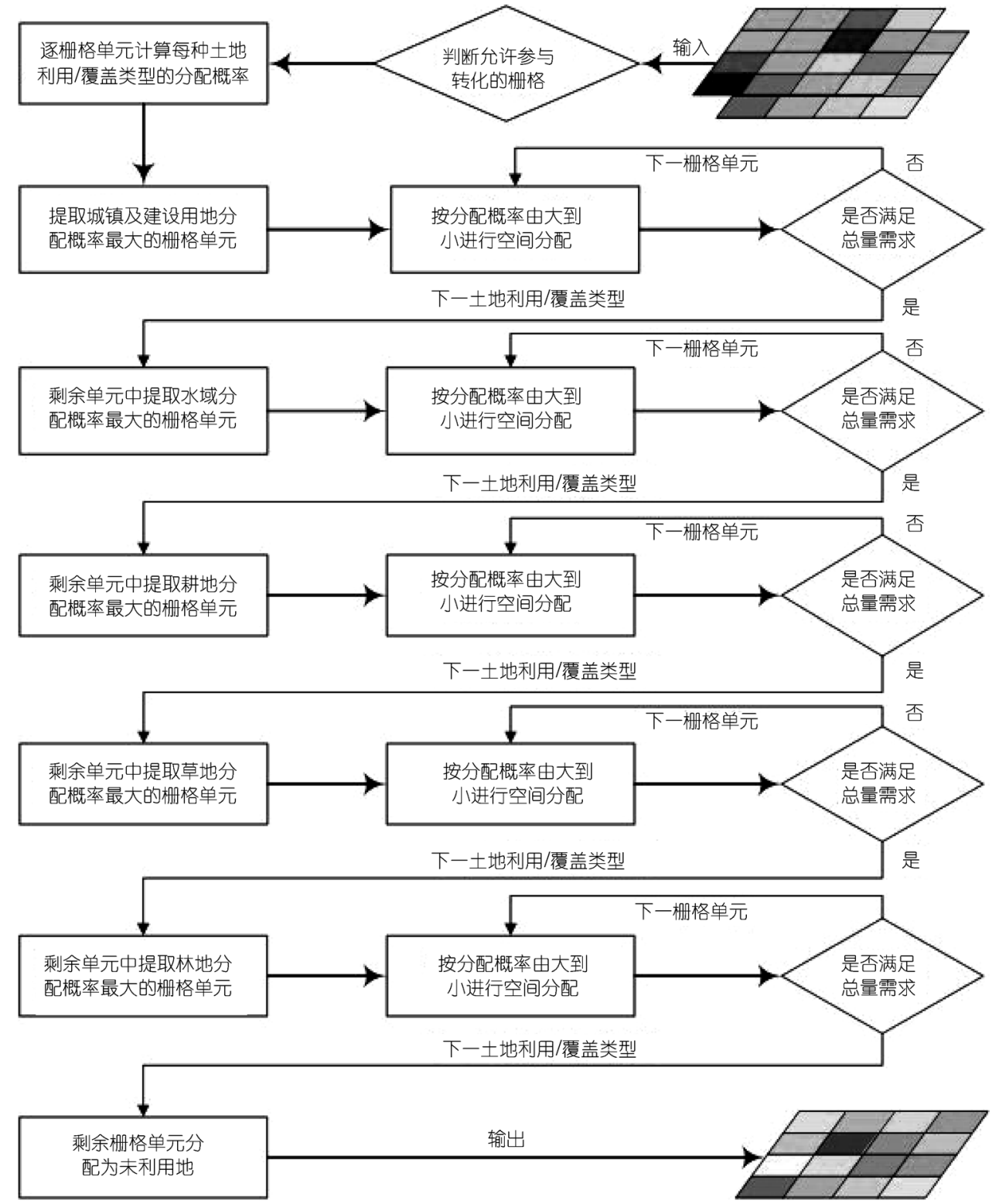

图 2 土地利用/覆盖变化空间分配原则 
量需求为止; (4) 滞后性规则: 模拟期内, 如果某栅 格单元被分配为某种土地利用/覆盖类型, 则不再考 虑该单元在此模拟期内的变化.

\section{2 北方 13 省(市)土地利用/覆盖时空变化的 预测与模拟}

\section{1 土地利用/覆盖总量需求预测}

本文利用作者前期研究成果建立的SD模型 ${ }^{[18]}$, 以 1987 2001 年的历史资料为基础(数据来源: 中国 国土资源年鉴、中国国土资源数据集、中国统计年鉴, 各省区统计年鉴, 中国地球系统科学数据共享网), 以 $5 \mathrm{a}$ 为时间间隔对研究区未来 $30 \mathrm{a}$ 不同情景下的土 地利用/覆盖变化的数量需求进行预测. 模型充分考 虑了人口、经济、市场调节、技术进步以及政府政策 调控的影响, 政府政策调控主要考虑退耕还林还草 等生态重建政策的影响, 并假设 2010 年前大于 $25^{\circ}$ 的坡耕地必须全部退耕. 几个因子的参数及情景设 置见表 1,2 , 预测结果见表 3.

\section{2 土地利用/覆盖时空变化模拟}

( i ) 数据处理. 空间模拟使用的数据包括研究 区 1989，1994 和 1999 三期土地利用/覆盖类型图(栅 格大小为 $1 \mathrm{~km})^{[32]}$; 中国 1:400 万基础数据(一级公 路、高速公路、铁路、县级以上城市驻地); 中国DEM 图(分辨率为 $1 \mathrm{~km}$ ). 研究表明土地利用/覆盖变化的 概率往往取决于栅格单元位置的一系列空间变量. 根 据研究区的特征以及CA模型的原理, 选取距离变量、 地形特征、气候要素、邻域影响等几个主要的影响因 素, 具体变量见表 4. 空间变量处理完成后, 还要进 行样本采集工作, 以便进行BP神经网络的训练. 样本 采集使用随机抽样的方法分别从三期土地利用/覆盖 图上各选取 5000 个样本点, 并分为两部分, 其
中 12000 个样本点进行 BP 神经网络的训练获取稳定 的网络连接权值, 另外 3000 个点作为验证数据用以 验证得到的网络是否满足精度要求.

(ii) BP神经网络结构的建立与训练. 本文使用 标准的三层BP神经网络. 输入层包括 16 个神经元 $(16$ 个空间变量), 输出层包括 6 个神经元 (6 种土地利用/ 覆盖类型). 对于一个三层 $\mathrm{BP}$ 网络, 隐含层神经元个 数可以用下面的经验公式计算 ${ }^{[29]}$ :

$$
S=\sqrt{0.43 k n+0.12 n^{2}+2.54 k+0.77 n+0.35}+0.5,
$$
其中, $S$ 为隐含层神经元个数, $k$ 为输入层神经元个数, $n$ 为输出层神经元个数. $S$ 的计算需要四舍五入法取 整, 然后增加 1 2 个增加收玫速度, 最终确定 BP 网 络隐含层神经元的个数为 12 . 建立的 BP 神经网络结 构为 16-12-6. 对于 BP 神经网络的输入变量, 在输入 前进行标准化处理, 以避免前后传播过程中的过饱 和现象; 对于网络的 6 个输出节点, 其输出编码分别 为: $[1,0,0,0,0,0]$ (耕地), $[0,1,0,0,0,0]$ (林地), $[0,0$, $1,0,0,0]$ (草地), $[0,0,0,1,0,0]$ (水域), $[0,0,0,0,1$, $0]$ (末利用地), $[0,0,0,0,0,1]$ (城建用地). 对输出结 果采用赢者全拿(Winner takes all)判别原则来确定该 样本所属类别. BP 神经网络结构建立后, 把训练样本 (12000 个)输入到网络中进行训练. 通过比较几种参 数设置的训练结果, 最终选择的训练参数设置和训 练结果见表 5 和 6 . 可以看出此 BP 神经网络测试精 度较高, 可以用来进行土地利用/覆盖变化的格局模 拟.

(iii) 基于 BPNN-CA 的土地利用/覆盖时空变化 模拟. 模型是在 ENVI环境下, 利用 IDL 语言实现的. $\mathrm{CA}$ 模型中各参数的权值由上述 BPNN 训练结果来确 定. 每次循环模型计算出每个像元对应各种土地利 用/覆盖类型的转换概率, 然后根据确定的转化规则,

\section{表 1 未来中国北方 13 省(市)土地利用/覆盖变化情景参数设置}

\begin{tabular}{lll}
\hline 情景参数 & & \multicolumn{1}{c}{ 参数设置 } \\
\hline GDP & 高增长率 $(\mathrm{E} 1)$ & 北方 13 省(市)经济保持每年 $7.5 \%$ 的增长速度 \\
& 中增长率 $(\mathrm{E} 2)$ & 北方 13 省(市)经济保持每年 $7.2 \%$ 的增长速度 \\
& 低增长率 $(\mathrm{E} 3)$ & 北方 13 省(市)经济保持每年 $7.0 \%$ 的增长速度 \\
& 快速增长型 $(\mathrm{P} 1)$ & 国家计划生育委员会对中国未来人口增长的预测结果 \\
& 稳定发展型 $(\mathrm{P} 2)$ & 中国人口信息研究中心对中国未来人口增长的预测结果 \\
& 低速发展型 $(\mathrm{P} 3)$ & 联合国对中国未来人口增长的预测结果 \\
& 开放输出 $(\mathrm{G} 1)$ & 粮食自给率为 1.07 \\
& 封闭平衡 $(\mathrm{G} 2)$ & 粮食自给率为 1 \\
& 开放输入 $(\mathrm{G} 3)$ & 粮食自给率为 0.95 \\
& 不考虑技术进步因素 $(\mathrm{T} 1)$ & 粮食单产维持 2000 年的现有水平 \\
& 考虑技术进步因素 $(\mathrm{T} 2)$ & 粮食单产 $2000 \sim 2015$ 年增长率为 $0.5 \%, 2016 \sim 2030$ 年增长率为 $0.4 \%$ \\
\hline
\end{tabular}


表 2 未来中国北方 13 省土地利用/覆盖变化驱动情景

\begin{tabular}{clll}
\hline 系统状态 & 状态说明 & & 情景说明 \\
\hline 封闭 & 封闭平衡 & 情景 $\mathrm{A}$ & 经济高速发展, 高人口增长, 粮食单产高于 2000 年水平 $\left(\mathrm{E}_{1} \mathrm{P}_{1} \mathrm{G}_{2} \mathrm{~T}_{2}\right)$ \\
& & 情景 $\mathrm{B}$ & 经济低速发展, 低人口增长, 粮食单产维持 2000 年水平 $\left(\mathrm{E}_{3} \mathrm{P}_{3} \mathrm{G}_{2} \mathrm{~T}_{1}\right)$ \\
& & 情景 $\mathrm{C}$ & 经济高速发展, 高人口增长, 粮食单产高于 2000 年水平 $\left(\mathrm{E}_{1} \mathrm{P}_{1} \mathrm{G}_{3} \mathrm{~T}_{2}\right)$ \\
& 开放 & 情放输入 & 经济低速发展, 低人口增长, 粮食单产维持 2000 年水平 $\left(\mathrm{E}_{3} \mathrm{P}_{3} \mathrm{G}_{3} \mathrm{~T}_{1}\right)$ \\
& & 情景 $\mathrm{E}$ & 经济高速发展, 高人口增长, 粮食单产高于 2000 年水平 $\left(\mathrm{E}_{1} \mathrm{P}_{1} \mathrm{G}_{1} \mathrm{~T}_{2}\right)$ \\
& 情景 $\mathrm{F}$ & 经济低速发展, 低人口增长, 粮食单产维持 2000 年水平 $\left(\mathrm{E}_{3} \mathrm{P}_{3} \mathrm{G}_{1} \mathrm{~T}_{1}\right)$ \\
\hline
\end{tabular}

表 3 未来中国北方 13 省(市)土地利用/覆盖类型面积总量需求情景预测

\begin{tabular}{|c|c|c|c|c|c|c|c|}
\hline 情景 & 年份 & 耕地 $/ \mathrm{km}^{2}$ & 林地 $/ \mathrm{km}^{2}$ & 草地 $/ \mathrm{km}^{2}$ & 水域 $/ \mathrm{km}^{2}$ & 未利用地 $/ \mathrm{km}^{2}$ & 城镇及建设用地 $/ \mathrm{km}^{2}$ \\
\hline \multirow[t]{6}{*}{ 情景 A } & 2005 & 541362 & 991851 & 2479865 & 71709 & 1106718 & 106086 \\
\hline & 2010 & 517981 & 1025784 & 2477111 & 74299 & 1090293 & 112123 \\
\hline & 2015 & 507100 & 1067989 & 2471171 & 76676 & 1055998 & 118658 \\
\hline & 2020 & 504999 & 1120570 & 2472938 & 80464 & 992816 & 125804 \\
\hline & 2025 & 499337 & 1166729 & 2474952 & 83812 & 939966 & 132795 \\
\hline & 2030 & 490325 & 1205344 & 2477054 & 86649 & 898914 & 139305 \\
\hline \multirow[t]{6}{*}{ 情景 B } & 2005 & 542005 & 990688 & 2480074 & 71616 & 1107374 & 105834 \\
\hline & 2010 & 520699 & 1022021 & 2477408 & 74009 & 1092003 & 111450 \\
\hline & 2015 & 502958 & 1059642 & 2472222 & 76039 & 1069475 & 117254 \\
\hline & 2020 & 499533 & 1107572 & 2473331 & 79484 & 1014094 & 123578 \\
\hline & 2025 & 492749 & 1158406 & 2476931 & 83051 & 956896 & 129557 \\
\hline & 2030 & 482535 & 1201587 & 2480730 & 86083 & 911858 & 134798 \\
\hline \multirow[t]{6}{*}{ 情景 C } & 2005 & 542651 & 986630 & 2485085 & 71709 & 1106718 & 104798 \\
\hline & 2010 & 519102 & 1020569 & 2482326 & 74299 & 1090293 & 111002 \\
\hline & 2015 & 496942 & 1062883 & 2477417 & 76676 & 1066203 & 117472 \\
\hline & 2020 & 481466 & 1116849 & 2478406 & 80556 & 1015767 & 124546 \\
\hline & 2025 & 476164 & 1167402 & 2481204 & 84177 & 957178 & 131467 \\
\hline & 2030 & 467665 & 1209228 & 2483879 & 87213 & 911694 & 137912 \\
\hline \multirow[t]{6}{*}{ 情景 D } & 2005 & 543063 & 985467 & 2485296 & 71616 & 1107374 & 104776 \\
\hline & 2010 & 521814 & 1016806 & 2482624 & 74009 & 1092003 & 110336 \\
\hline & 2015 & 503195 & 1054449 & 2477650 & 76039 & 1070177 & 116082 \\
\hline & 2020 & 476256 & 1102365 & 2478538 & 79484 & 1038606 & 122343 \\
\hline & 2025 & 469878 & 1153192 & 2482146 & 83051 & 981062 & 128262 \\
\hline & 2030 & 460227 & 1199926 & 2486583 & 86304 & 931101 & 133450 \\
\hline \multirow[t]{6}{*}{ 情景 E } & 2005 & 541893 & 989240 & 2482475 & 71709 & 1106718 & 105556 \\
\hline & 2010 & 530863 & 1023177 & 2479718 & 74299 & 1077972 & 111562 \\
\hline & 2015 & 542543 & 1065363 & 2473772 & 76676 & 1021173 & 118065 \\
\hline & 2020 & 540334 & 1113778 & 2474800 & 80205 & 963299 & 125175 \\
\hline & 2025 & 534303 & 1154252 & 2475814 & 83201 & 917890 & 132131 \\
\hline & 2030 & 524695 & 1188732 & 2477187 & 85782 & 882586 & 138608 \\
\hline \multirow[t]{6}{*}{ 情景 F } & 2005 & 542534 & 988078 & 2482685 & 71616 & 1107374 & 105305 \\
\hline & 2010 & 528573 & 1019414 & 2480016 & 74009 & 1084687 & 110893 \\
\hline & 2015 & 538127 & 1056957 & 2474198 & 76039 & 1035602 & 116668 \\
\hline & 2020 & 534468 & 1104450 & 2475843 & 79452 & 980418 & 122960 \\
\hline & 2025 & 527229 & 1149394 & 2478407 & 82655 & 930996 & 128910 \\
\hline & 2030 & 516326 & 1187819 & 2481370 & 85392 & 892560 & 134124 \\
\hline
\end{tabular}

在各种土地利用/覆盖类型总量的约束下, 模拟得到 研究区 LUCC 的情景格局. 模拟时, 各土地利用/覆 盖类型的继承性根据前面的转换规则并参考已有研 究成果的基础上分别设为: 耕地: 0.5 , 林地: 0.7 ; 草 地 0.3 , 水体 1.0 , 未利用地: 0.0 , 城建用地: $1.0 . \mathrm{a}$ 的
取值设为 0.02 , 将随机振荡因子 $r$ 的作用强度控制在 约 5\%之内. 模拟分两步进行, 首先, 以 1989 年和 1994 年研究区土地利用/覆盖类型图作为初始状态, 通过模型分别模拟 1994 年和 1999 年土地利用/覆盖 类型图 (见图 3), 以验证模型的有效性. 通过误差矩 
表 4 空间分配模块中使用的变量及计算方法

\begin{tabular}{|c|c|c|}
\hline 类型 & 名称 & 计算方法 \\
\hline 地形特征变量 & $\begin{array}{l}\text { 高程 }\left(x_{1}\right) \\
\text { 坡度 }\left(x_{2}\right) \\
\text { 坡向 }\left(x_{3}\right)\end{array}$ & $\begin{array}{l}\text { 在 DEM 数据的基础上利用 ARCGIS 的表面分析功能生成坡 } \\
\text { 度、坡向图, 然后直接从 DEM、坡度、坡向图上读取数据 }\end{array}$ \\
\hline 气候变量 & $\begin{array}{l}\text { 多年平均气温 }\left(x_{4}\right) \\
\text { 多年平均降水 }\left(x_{5}\right)\end{array}$ & $\begin{array}{l}\text { 利用全国 } 700 \text { 多个气象站点进行空间插值, 然后从栅格图中 } \\
\text { 读取数据 }\end{array}$ \\
\hline 距离变量 & $\begin{array}{l}\text { 距离县级行政单位驻地的距离 }\left(x_{6}\right) \\
\text { 距离地级以上行政单位驻地的距离 }\left(x_{7}\right) \\
\text { 距离高速公路的距离 }\left(x_{8}\right) \\
\text { 距离一级公路的距离 }\left(x_{9}\right) \\
\text { 距离铁路的距离 }\left(x_{10}\right)\end{array}$ & $\begin{array}{l}\text { 利用 ARCGIS 的距离分析功能生成距离棚格图, 然后从图上 } \\
\text { 读取数据 }\end{array}$ \\
\hline 邻域影响(5×5) & $\begin{array}{l}\text { 窗口内耕地对中心像元的影响 }\left(x_{11}\right) \\
\text { 窗口内林地对中心像元的影响 }\left(x_{12}\right) \\
\text { 窗口内草地对中心像元的影响 }\left(x_{13}\right) \\
\text { 窗口内水体地对中心像元的影响 }\left(x_{14}\right) \\
\text { 窗口内城镇及建设用地对中心像元的影响 }\left(x_{15}\right) \\
\text { 窗口内未利用地对中心像元的影响 }\left(x_{16}\right)\end{array}$ & $\begin{array}{l}\qquad N_{i}=\sum_{m=-2}^{2} \sum_{n=-2}^{2} \frac{\text { class }_{m, n}}{d_{m, n}}, \\
N_{i} \text { 为窗口内 } i \text { 类土地利用/覆盖类型对中心像元的影响; } \\
\operatorname{class}_{m, n} \text { 为窗口内 }(m, n) \text { 处的土地利用/覆盖类型, 为一二值变 } \\
\text { 量, 如果 }(m, n) \text { 处的土地利用/覆盖类型为 } i \text { 则 } \operatorname{class}_{m, n}=1 \text {, 否则 } \\
\operatorname{class}_{m, n}=0 ; d_{m, n} \text { 为窗口内 }(m, n) \text { 像元距离中心像元的距离. 利 } \\
\text { 用 IDL 编程实现 }\end{array}$ \\
\hline
\end{tabular}

表 5 BP 神经网络训练参数设置

\begin{tabular}{|c|c|c|c|c|c|}
\hline 参数名称 & 最小训练速率 & 动态参数 & 允许误差 & 最大迭代次数 & 激发函数 \\
\hline 参数值 & 0.05 & 0.7 & 0.00001 & 10000 & Sigmoid \\
\hline 参数说明 & $\begin{array}{l}\text { 训练速率越大, 权值变化越大, 收玫越快; } \\
\text { 但训练速率过大会引起系统的振荡. 训练 } \\
\text { 速率在不导致振荡的前提下, 越大越好. } \\
\text { 一般由经验确定 }\end{array}$ & $\begin{array}{l}\text { 动态参数的选 } \\
\text { 择也是由经验 } \\
\text { 确定 }\end{array}$ & $\begin{array}{l}\text { 当 } 2 \text { 次迭代误差 } \\
\text { 小于该值时, 系 } \\
\text { 统结束迭代运算 }\end{array}$ & $\begin{array}{l}\text { 神经网络并不能保证迭代结 } \\
\text { 果一定收玫, 当迭代结果不收 } \\
\text { 玫, 但达到最大迭代次数时, } \\
\text { 系统结束运算 }\end{array}$ & \\
\hline
\end{tabular}

表 6 BP 神经网络训练结果精度分析 $(\%)$

\begin{tabular}{ccccccc}
\hline 类型 & 耕地 & 林地 & 草地 & 水域 & 未利用地 & 总体 \\
\hline 训练精度 & 79.91 & 87.45 & 94.24 & 93.18 & 94.49 \\
验证精度 & 79.00 & 88.06 & 93.80 & 89.77 & 95.35 & 94.05 \\
\hline
\end{tabular}
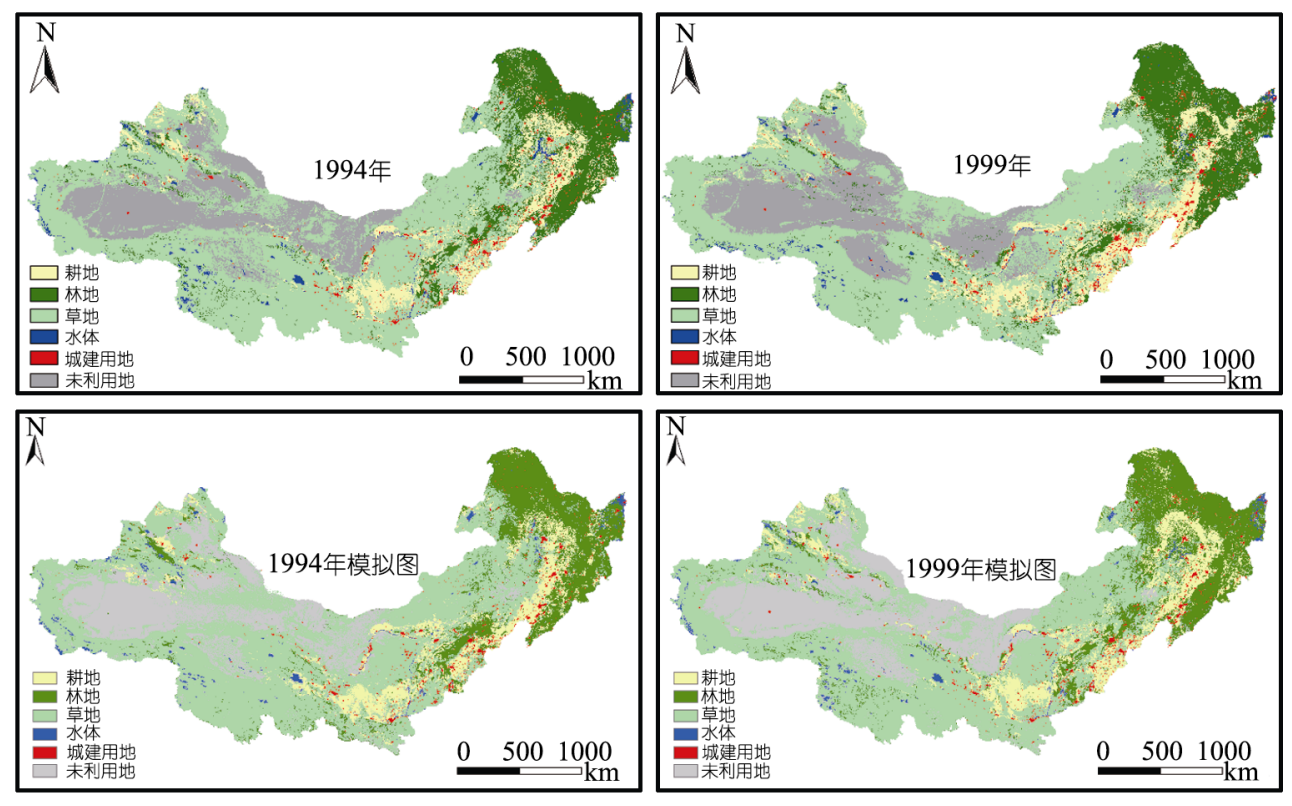

图 31994 和 1999 年土地利用/覆盖模拟结果 
阵分析可以看出模拟结果的 kappa 系数均在 0.6 以上, 总精度也都超过了 $70 \%$ (见表 7). 说明模型在一定程 度上能反映区域土地利用/覆盖空间格局演化特征. 其次, 利用该模型以 $\mathrm{SD}$ 情景预测结果为依据，模拟 未来 $30 \mathrm{a}$ 研究区土地利用/覆盖变化 6 种不同情景(见 表 1,2,3)下的时空格局(见图 4).

\section{3 结果分析}

与前期研究建立的LUSD模型 ${ }^{[6]}$ 相比, BPNN-CA 模型有了很大的改进和完善. (i ) LUSD模型中, 微 观格局演化模拟仅考虑了地形和交通要素, 气温、降 水以及除交通以外的区位条件的影响均未考虑. 本 文研究中对这些要素及不同土地利用/覆盖类型的邻 域影响, 土地利用/覆盖类型的继承性以及随机因素 的影响均加以考虑. 土地利用/覆盖系统是一个复杂 系统, 它的演变不是通过简单的地形和交通要素就 能决定的, 综合考虑多种可能驱动因子的影响能够 提高模拟结果的真实性. (ii ) LUSD模型中所有影响 微观格局演化的要素作用权值的确定全部依靠人为 设定. 这样虽然能够融入专家知识, 但由于不同人对 问题认识的角度不同, 必然导致因子权值的取值差 异. 可见这种方法主观随意性较大，同时也增加了模 型参数订正的工作量. 而BPNN-CA模型把神经网络 方法引入 $\mathrm{CA}$ 模型来确定各影响因子的权值, 简化了 模拟过程中参量权重确定问题，增强了权重确定的 客观性. (iii) LUSD模型为了简化, 假设难利用地和
水体维持在 1999 年水平上保持不变, 仅考虑耕地、 林地、草地和城建用地等 4 种土地利用/覆盖类型的 动态变化, 显然与实际情况有所差异. BPNN-CA 模 型在进行空间格局模拟时考虑了研究区一级分类系 统下的所有土地利用/覆盖类型的动态变化和空间格 局演变模拟. 虽然两者总体模拟精度基本相当, 但 BPNN-CA 模型一方面能够简化模拟过程参数权值的 设置, 减少人为参与的工作量, 提高模拟结果的客观 性; 另一方面它考虑了所有土地利用/覆盖类型的数量 变化和空间格局演变, 较 LUSD 模型更符合实际情况. (iv) 本文模型在情景参数设置时除了考虑人口、经 济、市场调节、技术进步等因素外还考虑了生态重建, 如退耕还林还草等政府政策调控因素的影响. 在过 去的十几年内中国政府已经实施和正在实施了大量 生态建设工程. 如正在实施的“西部大开发战略”, 把 生态环境改善与建设作为五项重要工作之首, 给予 高度重视, 相继实施了“天然林保护工程”、“退耕还林 还草”.同时，作为对中国 2000 年特大沙尘暴灾害的响 应，中国北方还实施了“首都圈裸地沙化防治工程”、 “退牧还草工程”、“塔里木河流域综合治理工程”等. 这一系列工程的实施, 对中国北方土地利用/覆盖的 方式、强度和格局, 将产生重要的影响. 在情景参数 设置时考虑这些生态环境重建等政府政策调控因素 的影响, 显然有助于提高模拟结果的可靠性. 因此, BPNN-CA 模型的模拟结果的科学性、可靠性和模拟 精度实际上均优于前期建立的 LUSD 模型.

表 71994 与 1999 年研究区模拟与实际土地利用/覆盖误差矩阵 $(\%)$

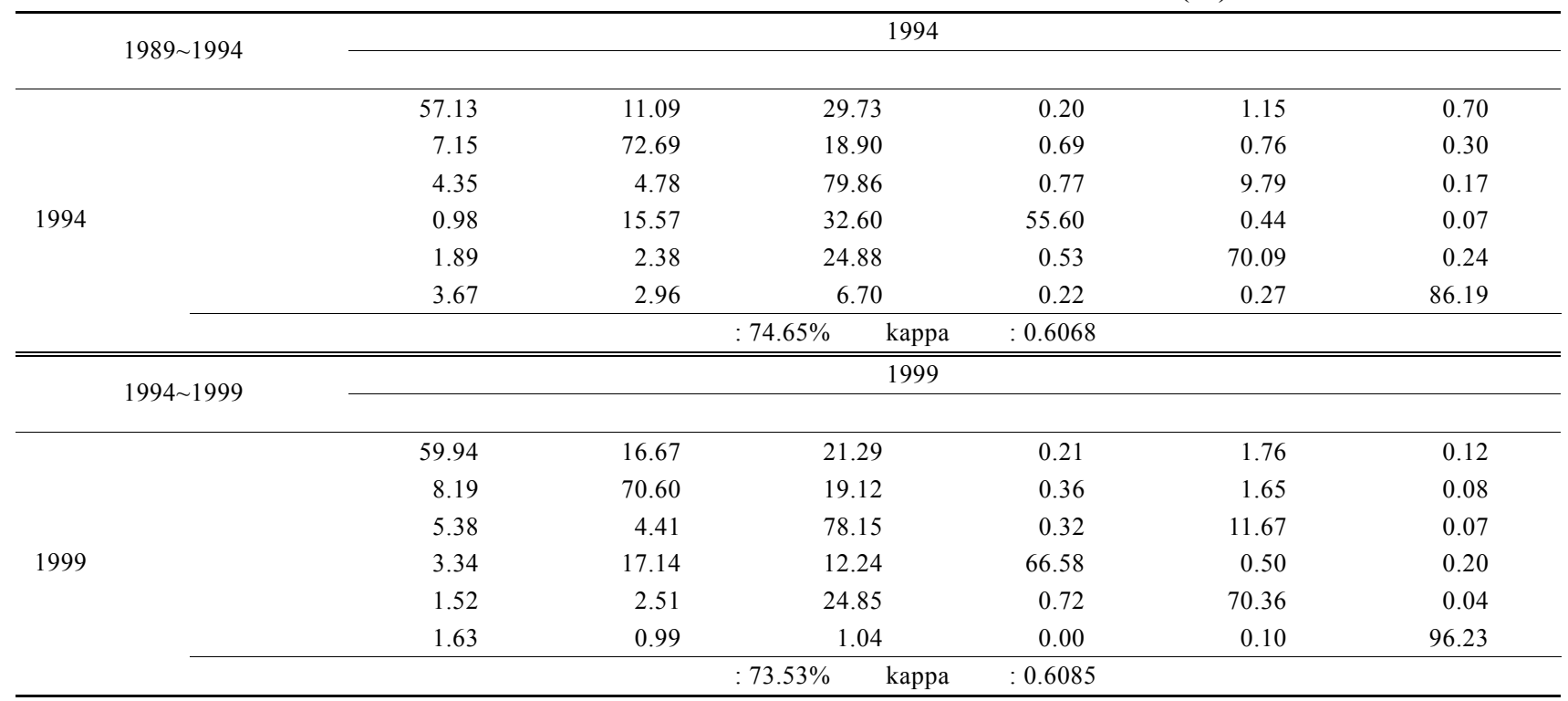



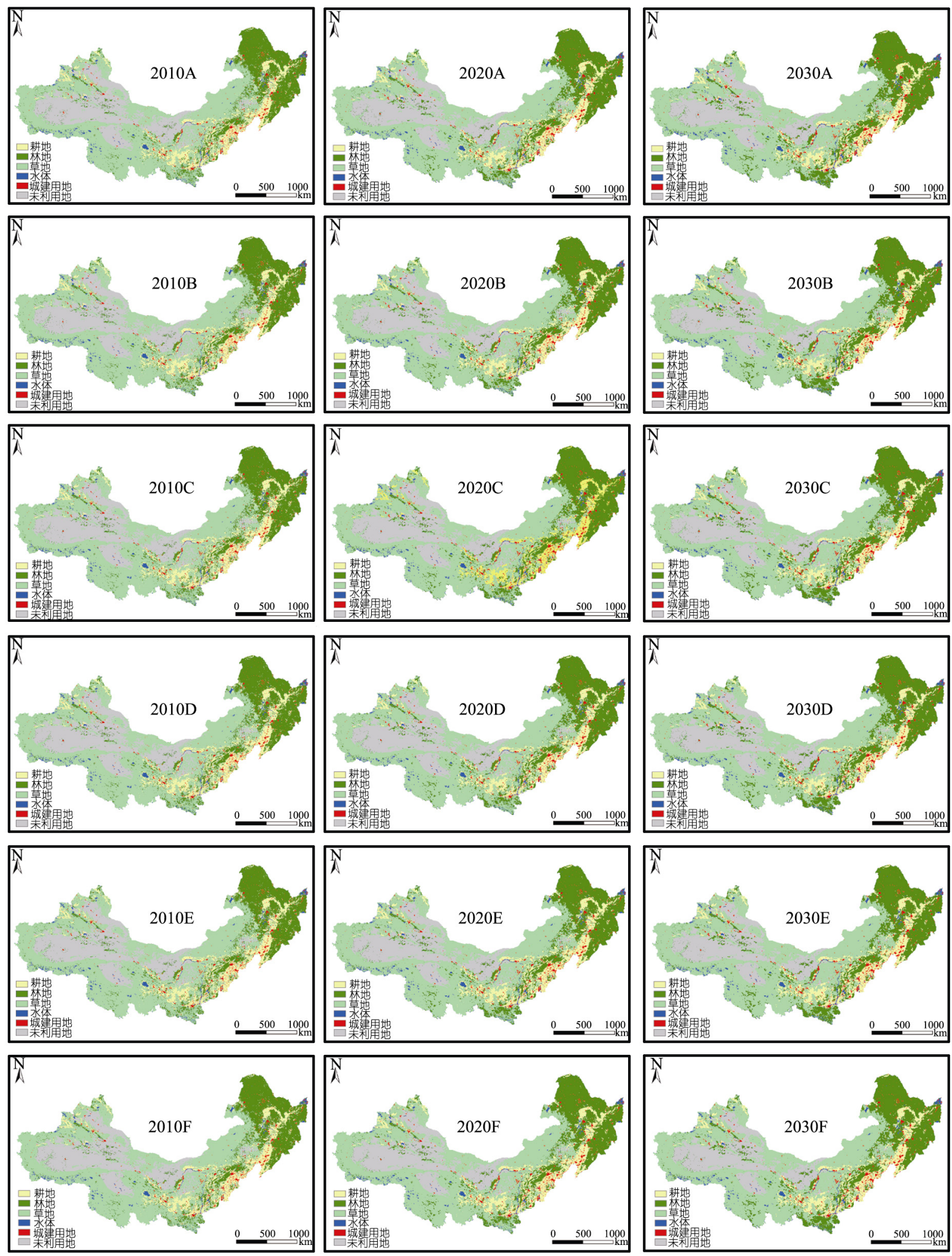

图 4 研究区 1999 2030 年土地利用/覆盖模拟结果 
从模拟和预测的数量特征分析, 虽然 6 种情景有 所差异, 但仍能表现出共同的特征. 耕地和城建用地 表现出基本相反的动态变化趋势. 在 2005 2030 年模 拟期内, 耕地呈现明显的持续减少趋势, 以情景 C 和 $\mathrm{D}$ 减少最为显著, 减少比例均在 $10 \%$ 以上; 城建用地 则呈现出明显的持续增加趋势, 情景 $\mathrm{A}, \mathrm{E}$ 和 $\mathrm{C}$ 增加 趋势最明显, 增长比例都超过了 $30 \%$. 林地、草地和 水域作为区内重要的生态功能用地也表现出不同的 变化特征, 林地在模拟期内持续增长, 情景 $\mathrm{C}$ 增长幅 度最大, 增长比例超过了 $22 \%$, 情景 $\mathrm{E}$ 和 $\mathrm{F}$ 增长比例 最小, 约为 $20 \%$; 草地变化相对比较稳定, 各情景中 在 2015 年前, 草地表现出缓慢减少趋势, 2015 年后 则逐渐增加, 到 2030 年基本恢复到 2005 年的水平; 水域在区域内变化也比较明显, 各情景下水域面积 均有所增加, 情景 C 增加比例最大, 超过了 $21 \%$, 情 景 $\mathrm{F}$ 增加比例最小约为 $19 \%$. 未利用地作为一种负生 态功能用地, 其变化对区域生态环境质量有着重要 影响.在本文设置的 6 个情景中, 未利用地均表现出 不同程度的减少, 其中情景 $\mathrm{E}$ 变化幅度最大, 约减少 了 $20 \%$, 情景 D 减少幅度最小, 约为 $16 \%$. 林地、水 体等高生态功能用地持续增长, 未利用地等负生态 功能用地持续减少，增强了区域生态系统的自我恢 复域调节能力, 降低了生态系统的脆弱性. 未来几十 年研究区的土地利用利用/覆盖若能按照模拟情景发 展, 将有利于区域生态环境质量的不断提高. 同时, 区域耕地面积不断减少，但人口规模则在一定时期 内仍然呈现增长趋势, 粮食安全问题也将是研究区 未来面临的一个重要问题. 从模拟结果的空间格局特 征分析, 农牧交错带是中国北方末来几十年土地利用/ 覆盖变化比较明显的地区, 而耕地和城镇用地是农 牧交错带内变化最为显著的两种用地类型. 区域城 建用地的变化主要是在原有城镇用地的基础上向外 扩展. 未利用地的变化主要发生在与其他用地类
型邻接的边缘地区，这些地区在各种因子的作用下， 用地条件逐渐好转, 转化为相应的土地利用/覆盖类 型, 主要以向草地的转化为主. 区内林地增长比较明 显的地区主要分布在内蒙古东北部、黑龙江、吉林、 辽宁以及京津周边地区. 发生变化的部位主要是林 地-耕地, 林地-草地的交接地带. 表明国家一系列的 生态调控措施在这些地区发挥着重要作用.

\section{4 结论与讨论}

（i ）“自上而下”与“自下而上”相结合，综合考虑 土地利用/覆盖变化宏观驱动因素复杂性和微观空间 格局演化过程复杂性特征的土地利用/覆盖变化模拟 与预测模型是土地利用/覆盖变化研究有意义的探索.

(ii) CA 的空间模拟精度很大程度上受各变量参 数设置是否合理的制约. 只有获得合适的变量参数 才能得到接近实际的模拟结果. BP 神经网络确定 CA 模型各空间参量的作用权值, 简化了 CA 模型模拟过 程中参量权重确定问题, 提高了参量权值确定的精 度. 当 $\mathrm{BP}$ 神经网络训练完成后, 由训练确定的网络 就可用于求解相同的问题. 对于不同的研究区域, 只 需要提供相应区域的训练样本就可以得到较为理想 的模拟结果, 与已有的类似模型相比具有一定优势. 模拟结果表明, 基于 BPNN-CA 方法对研究区进行的 土地利用/覆盖变化空间格局模拟的总精度约 $74 \%$, kappa 系数在 0.6 以上, 对于大区域土地利用覆盖变 化研究而言能够在一定程度上反映区域土地利用/覆 盖变化的空间格局演变特征.

（iii）模拟结果只是一种“可能情况”, 具有一定 的不确定性, 有时可能还会出现与实际情况不一致 的情况. 但选择典型地区, 探讨发展土地利用/覆盖 情景模型, 预测不远将来不同情景下的土地利用/覆 盖时空变化格局, 对于揭示土地利用/覆盖系统变化 的动态机制仍然具有一定意义. 心的感谢.

\section{参考文献}

1 Dawn C P, Steven M M, Marco A J, et al. Multi-Agent systems for the simulation of land-use and land-cover change: A review. Ann Assoc Am Geogr, 2002, 8: 93-100 
Comput Environ Urban Syst, 2002, 26(6): 553-575[DOI]

摆万奇，赵世洞。土地利用/覆盖变化研究模型综述. 自然资源学报, 1997, 12(2): 169-175

Veldkamp A, Fresco L O. CLUE: A conceptual model to study the conversion of land use and its effects. Ecol Model, 1996, 85: 253 $-270 \underline{[\mathrm{DOI}]}$

何春阳, 陈晋, 史培军, 等. 大都市区城市扩展模型一以北京城市扩展模拟为例. 地理学报, 2003, 58(2): 294一-304

何春阳, 史培军, 陈晋, 等. 基于系统动力学模型和元胞自动机模型的土地利用情景模型研究. 中国科学 D 辑: 地球科学, 2005, 35(5): 464-473

熊利亚, 常斌, 周相广. 基于地理元胞自动机的土地利用变化研究. 资源科学, 2005, 27(4): 38-43

Verda K, Suzana D. Coupling Bayesian networks with GIS-based cellular automata for modeling land use change. Lecture Notes Comput Sci, 2006, 4197: 217-233

Lambin E F, Turner B L, Geist H J, et al. The causes of land use and land cover change: Moving beyond the myths. Global Environ Change, 2001, 11: 261-269 [DOI]

Lambin E F, Rounsevell M D A, Geist H J. Are agricultural land-use models able to predict changes in land-use intensity? Agric Ecosyst Environ, 2000, 82: 321-331 [DOI]

李月臣. 北方 13 省土地利用/覆盖变化问题研究. 博士学位论文. 北京: 北京师范大学, 2006.94-97

张华, 张勃. 国际土地利用/覆盖变化模型研究综述. 自然资源学报, 2005, 20(3): 422-431

周成虎, 孙战利, 谢一春. 地理元胞自动机研究. 北京: 科学出版社, 1999. 78-103

张汉雄. 晋陕黄土丘陵区土地利用与土壤侵蚀机制仿真研究. 科学通报, 1997, 42(7): 743-746

苏惁康. 系统动力学原理及应用. 上海: 上海交通大学出版社, 1988. 86-98

史培军, 宋常青, 景贵飞. 加强中国土地利用/覆盖变化及其对生态环境安全影响的研究. 地球科学进展, 2002, 17(2): 161一 168

张永民, 赵士洞, Verburg P H. CLUE-S 模型及其在奈曼旗土地利用时空动态变化模拟中的应用. 自然资源学, 2003, 18(3): 310318

何春阳，史培军，李景刚，等. 中国北方未来土地利用变化情景模拟. 地理学报, 2004, 59(4): 599-607

Couclelis H. From cellular automaton to urban models: New principles for model development and implementation. Environ Plann B, 1997, 24: 165-174ㅁD]

Zhao Y I, Yu J M. A new method to model neighborhood interaction in cellular automata-based urban geosimulation. Lecture Notes Comput Sci, 2007, 4488: 550-557

黎夏, 叶嘉安. 基于神经网络的单元自动机 CA 及真实和优化的城市模拟. 地理学报, 2002, 57(2): 159-166

Batty M, Xie Y, Sun Z. Modeling urban dynamics through GIS-based cellular automata. Comput Environ Urban Syst, 1999, 23: 1$29 \underline{[\mathrm{DOI}]}$

3 Li X, Liu X P. An extended cellular automaton using case-based reasoning for simulating urban. Int J Geograph Inform Sci, 2006, 20(10): 1109-1136 [DOI]

Wu F, Webster C J. Simulation of land development through the integration of cellular automata and multicriteria evaluation. Environ Plann B, 1998, 25: 103-126미]

黎夏, 叶嘉安. 知识发现及地理元胞自动机. 中国科学 D 辑: 地球科学, 2004, 34(9): 865-872

刘小平, 黎夏. 从高维特征空间中获取元胞自动机的非线性转换规则. 地理学报, 2006,61(6): 663-672

Li X, Yeh A G O. Data mining of cellular automata's transition rules. Int J Geograph Inform Sci, 2004, 18(8): 723-744[DOI]

刘小平, 黎夏, 叶喜安, 等. 利用纹群智能控掘地理元胞自动机的转换规则. 中国科学 D 辑: 地球科学, 2007, 37(6): 824一834

White H. Commentionist nonparametric regression: Multilayer feedforward networks can learn arbitrary mapping. Neural Netw, 1990, (3): $47-51$

杨建刚. 人工神经网络实用教程. 浙江: 浙江大学出版社, 2001. 56-72

张立明. 人工神经网络的模型及其应用. 上海: 复旦大学出版社, 1993. 36-48

李月臣，宫鹏，陈晋，等．中国北方 13 省土地利用景观格局变化分析(1989 1999). 水土报持学报, 2005, 19(5): 143-146 